REVISTA CHILENA DE LITERATURA

Noviembre 2019, Número 100, 261-277

\title{
VITALIDAD PATÉTICA
}

\author{
Liliana Patricia Marlés Valencia \\ Doctora en Letras \\ São Paulo, Brasil \\ lilianamarles@hotmail.com
}

\begin{abstract}
RESUMEN / ABSTRACT
José Donoso señaló su interés por la emoción como ingrediente y efecto literario. Este texto reconoce el funcionamiento de una estética donosiana que promueve la inserción del pathos a partir del uso paródico de la economía emotiva de la tragedia. El escritor moviliza diversos componentes novelescos en la búsqueda de una experiencia mítica en que el lector asiste a la sacralización del despojo. Un mecanismo que será recurrente en la escritura donosiana y que este texto sondea a partir de su primera novela, Coronación (1957).
\end{abstract}

Palabras ClaVe: pathos, tragedia, mito, parodia, José Donoso.

\section{PATHETIC VITALITY}

José Donoso pointed out his interest in emotion as literary ingredient and effect. This text recognizes the operation of a donosian aesthetics that promotes the inclusion of pathos through a parody of the emotive economics of tragedy. The author articulates different novelistic elements in search of a mythical experience for the reader who witnesses the sacralization of waste. This mechanism persists throughout Donoso's production and its examination will take into account his first novel, Coronación (1957).

KEYWORDS: pathos, tragedy, myth, parody, José Donoso.

Recepción: 19/03/2018

Aprobación: 18/05/2018 
Suelen ser novelas un poco duras, sin oscilación, divertidas, agudas, inteligentísimas, a veces encantadoras, pero carentes de todo pathos

Conjeturas sobre la memoria de mi tribu José Donoso

La adversativa pero en esta afirmación de José Donoso, sobre las lecturas de su preferencia, resume algo fundamental de su propia estética. Se entiende aquí por estética lo mismo los conceptos y teorías implícitas en la creación como su sentido original de aisthesis (percepción), es decir, como referida al conocimiento sensorial, en contraste con el conocimiento conceptual. A pesar de su reconocimiento de virtudes como la inteligencia y la agudeza en el ejercicio escritural, a medio camino entre divertido y condescendiente, Donoso admite que esas virtudes no le bastan. Una parte de la experiencia humana que no se limita a las herramientas tradicionales del conocimiento científico le interesa particularmente. De esta curiosidad surge una estética de la literatura como lugar para el desborde de lo puramente racional. Más que eso, como un ejercicio del vértigo que se constituye en forma literaria.

En Coronación cada acción contribuye de manera evidente al desarrollo de la trama, salvo la escena que da título a la novela. Esta celebración, que puede parecer apenas contingente, moviliza la parodia de un mito. A pesar del toque cómico en ella, este efecto paródico está lejos de desvirtuar su carácter ritual. Por el contrario, a través de esta escena es convocado el poder del mito y con él se despliega la experiencia mítica que conlleva al efecto emocional/ patético que fascinaba al autor y que es central a su estética.

\section{PATHOS}

La palabra está relacionada con el verbo paskho que quiere decir sufrir o experimentar ${ }^{1}$, y nos sitúa en conexión casi directa con la tragedia, un 
género cuya razón de ser primordial es el efecto emotivo (Konstan 3-27). Su economía emotiva, el término es de Malcolm Heath, busca dar vía libre a los impulsos, de modo que el espectador satisfaga el deseo de asomarse al abismo y derivar de esto un placer inofensivo (Heath 98-107). La tragedia no tiene una obligación edificante, pues su compromiso no es con la verdad, de donde surge la valoración de la ficción poética como artificio, perspectiva tan cara a la poética donosiana. Hay un vínculo transversal al concepto de pathos apenas citado por Donoso en la declaración que funciona como epígrafe de este texto, el proferido por sus personajes y el establecido alrededor de la tragedia.

George Steiner reflexiona agudamente sobre la historicidad y transformación del género trágico. Dirá que la desaparición de la cosmovisión mitológica y ritual de donde era propia tuvo consecuencias contundentes para la tragedia $(243-267)^{2}$. De manera que para abordar este tipo de asuntos en un contexto contemporáneo, el autor deberá ejecutar no solo transformaciones de forma -el verso contribuía a la sensación de solemnidad que hoy en día puede lucir anacrónica-, sino también aquellas que integren una visión burguesa a tono con su contemporaneidad, como han señalado también otros estudiosos (Mulinacci 2004). Esto resume la maniobra utilizada por José Donoso: inclusión de personajes con una carga trágica y brutal que, al mismo tiempo, son alivianados por la ironía.

El novelista acentúa, en entrevista, su interés por la compasión como un efecto literario (Rodríguez Monegal 533). Emanación que solo puede lograrse dentro del modo trágico en que el héroe es apartado de la sociedad. En ese caso, podrá situarse ya sea en la categoría de lo mimético bajo donde

manera directa frente al sufrimiento del otro, sino tras un juicio que comprobara el merecimiento de tal compasión. Del mismo modo, el término puede significar cualquier cosa que denote reacción a una experiencia (LaCourse 1-26).

En La muerte de la tragedia, Steiner defiende que un mundo que gira alrededor de la idea de justicia no podía ser concomitante con la tragedia, tan ajena al remordimiento, ámbito del dominio privado y no del dominio de lo público al que pertenece. A partir de la conquista del racionalismo, el género transmuta en sentido técnico y se vuelve escaso lugar de asuntos trágicos. El/la artista que quiera crear su propia mitología tendrá que librar una batalla casi imposible con el tiempo para lograr que el público pueda establecerse en el código -mitología- que proponga. Esto deja otra opción que, lo mismo, plantea problemas: acudir a una mitología ya instalada que pueda ser moneda corriente para quien se acerca a la obra. Solo cuando se establece ese repertorio en común se puede generar una respuesta contundente de parte del espectador. 
no es superior ni a otros hombres ni a su alrededor, o en la ironía, donde es inferior al lector tanto en poder como en inteligencia, para usar los conceptos de Northrop Frye. En Anatomía de la crítica, justamente, se hace alusión al bajo mimético como tragedia doméstica o pathos (Frye 35-43). Aunque no se puede descartar ni admitir el hecho de que Donoso haya tenido algún contacto con esta teoría, lo significativo es que su idea de pathos y la del crítico canadiense contienen similitudes que arrojan luz sobre la estética que aquí se señala.

El novelista no explica de manera rotunda a qué se refiere con el término pathos, pero lo menciona una vez en Conjeturas sobre la memoria de mi tribu (1996) como una cualidad de la que a veces adolecen novelas a las que, sin embargo, no les falta creatividad o inteligencia. Por su parte, el crítico lo usa como un modo ficcional en que el héroe apela a la simpatía del lector por la cercanía con que es representada la dureza de su destino (Frye 38-39). Como ejemplos, menciona a personajes tanto de Henry James como de Virginia Wolf, dos escritores que han sido reconocidas influencias donosianas. La ironía en Donoso proviene del mimético bajo y se desplaza desde el realismo hasta encontrar un matiz mítico, donde se cubre de un aspecto ritual. La obra donosiana es una apuesta estética que procura crear un efecto emocional en el lector desde el enunciado y desde la enunciación. Puesto que el efecto al que se refiere el autor es la compasión, se requiere de una economía ficcional que incluya personajes y situaciones con una carga funesta - para garantizar el espasmo propio del vértigo-, pero que a la vez permitan una cercanía con el lector contemporáneo y su visión desencantada del mundo.

La figura del dios Hermes en su pluralidad paradójica representa el aspecto trasgresor y a la vez consagrante del procedimiento paródico (Hutcheon xvii). Entraña un potencial de reordenamiento al permitir que elementos bajos y sin importancia se conviertan en centrales en la versión paródica. En Donoso, ese rebajamiento nada tiene que ver con banalización, abarca un amplio rango de tergiversaciones y mezclas de diversos matices. Escenas míticas conforman un potencial que Donoso aprovecha, entre otras cosas, por la fuerte presencia que tienen en el imaginario del lector. No es pura coincidencia la alusión que hace en su diario, el 20 de enero de 1965, al libro de George Steiner: La muerte de la tragedia (1991), como uno de los que necesitaba leer.

Ahora bien, las acciones míticas se llevan a cabo con un trasfondo de pasado prestigioso. De modo similar, Donoso usa un tiempo remoto pero con los tintes de nostalgia apenas suficientes para resaltar el presente que se desliza hacia su decadencia. Es una larga tradición de escritores la que ha 
hecho uso de insumos mitológicos. La presencia de figuras míticas es común entre los modernos, sin embargo, no siempre se busca la experiencia mítica. En el caso donosiano, esta cuestión toma relieve y es necesario discernir el matiz de esa experiencia. Mircea Eliade sostiene que vivir este tipo de relatos exige una actitud religiosa, en tanto es vivencia que se aparta de la cotidianidad (Eliade 24). Como se ha visto a partir de sus declaraciones, esta es una exploración a la que el novelista otorga un lugar central: sacudir la emoción del lector.

La novela plantea una experiencia en que lo cotidiano se sacraliza a través de su destrucción. La degradación no es el estado final, sino el medio por el que se opera la transformación sagrada. De allí que la visión de mundo no se limite a aquella que se confiere por medio de los saberes de una racionalidad demostrativa propia del logos o una causalidad expresa, sino que su funcionamiento se manifieste dentro de la intuición y la asociación, para citar las formas que despliega Ernst Cassirer ${ }^{3}$. El proyecto donosiano va más allá del viejo dilema de la emoción o la razón. Construye, propone y desarrolla una propuesta escritural que usa el mito como apropiación de una forma y, sin detenerse en esto, se dirige a la "experiencia" propia del mismo. Parodiar el mito es su manera de apropiarse de él, ya que al despedazarlo lo acerca y renueva su vigencia.

Al hablar de la diferencia entre alegoría y mito, Maurice Blanchot llama la atención sobre el hecho de que la primera establezca una relación significante/ significado, mientras que el segundo funde una verdadera presencia. De allí que entrar en el modo mítico corresponda a una acción que se lleva a cabo en presencia del mito -con la verdad que él mismo funda- no como mera representación, y sí para abrirse a un sentimiento, es decir, a una experiencia. Alcanzarla se constituye en un medio para expresar no lo que se sabe sino para

Cassirer, Ernst. Filosofía de las formas simbólicas. 1964, V. 2. Este volumen expone las divergencias entre la forma de pensamiento mítico y la forma de pensamiento teórico. El mito conlleva una forma de percibir el mundo divergente de la del pensamiento teórico. El primero capta el mundo mediante una visión de la realidad como indiferenciada y homogénea, es decir, se aleja de la distinción entre grados delimitados de certeza objetiva propia del pensamiento teórico. Esto implica la abolición de las diferencias de planos. Dentro del mito, no hay discrepancia entre vigilia/sueño, vida/muerte $u$ original/copia. Esta es una característica fácilmente rastreable en la narrativa donosiana, sobre todo en una novela como El obsceno pájaro de la noche (Donoso 1970) donde las múltiples transformaciones se suceden sin barreras o límites fijos. 
sentir lo que no se sabe (Blanchot 102). El uso paródico del mito incluye un contenido representativo provechoso y pasible de diversas interpretaciones pero que no debe detenerse en una lectura netamente alegórica. Donoso pondera: "llegar a la vivencia de esta no-unidad del ser humano causa horribles angustias y horribles dolores" (Rodríguez Monegal 1971: 525). A partir de la alusión a ese carácter de sufrimiento, emerge más clara la afinidad del escritor con la potencialidad del mito para promover la emoción.

Así, es posible seguir la pista del mito no apenas como alegoría en el insumo paródico. Se puede indagar su presencia a un nivel que corresponde a una forma de pensamiento que a su vez impacta la forma literaria donosiana. La importancia que el autor da a esta forma de pensamiento coincide con su interés por la literatura dentro del orden de lo inútil y pasajero, por encima de la aspiración a lo permanente y necesario, propia del pensamiento teórico.

\section{BACANTES SANTIAGUINAS: CORONACIÓN}

Cedomil Goic, en La novela chilena: los mitos degradados, se ha referido a la novela contemporánea como lugar del triunfo de la conciencia mítica sobre el ciego cientificismo que se imponía en la novela moderna (14). Dado el reconocimiento de la complejidad propia de la existencia que Coronación plantea, tal como lo demuestra el crítico en el capítulo que dedica a la obra (163-176), se desarrolla un rompimiento con las formas representativas de la realidad tomada como natural. Esto desemboca en la vigencia de una conciencia mítica y metafísica. Además, la estructura de la novela apunta a la superación del orden que promete univocidad, por eso "A los modos genéticos y causales de las mecanicistas formas de la experiencia tradicional suceden los modos inmediatos o existenciales de la experiencia personal" que se abren a modos diversos de conciencia o in-conciencia (169).

Ahora bien, la escena en que las sirvientas coronan a Misia Elisita participa de manera esencial en ese "triunfo" de lo mítico, dado que con ella se introduce narrativamente un tratamiento de la causalidad que se aviene con el mito y su forma de pensamiento. El modo de funcionamiento de las causas y efectos es una faceta discrepante entre pensamiento teórico y mítico; si bien está presente en ambas formas, lo que varía es su modalidad. El pensamiento teórico analiza y separa en unidades la realidad hasta comprobar la relación causa-efecto. Ya en el pensamiento mítico, la causalidad se genera por una relación de contigüidad que puede ser espacial o temporal (Cassirer 
51-88). Una característica en que vale la pena detenerse porque es bajo este reconocimiento que se entiende mejor la magnitud de la "coronación" en esta primera novela del autor. Esta coronación suscita cambios que se asimilan a través de la idea de contigüidad y, por tanto, de la prevalencia del pensamiento mítico. Escena imprescindible porque encierra una apuesta autorial: destacar un rito inútil dentro del orden lógico de los acontecimientos pero cargado de un significado profundo dentro del orden de lo narrativo.

"Debo, además, hacer un hincapié temprano en la novela, sobre la idea de la coronación. De alguna manera debo dar a entender antes del capítulo 24 que va a haber una coronación absurda, y de lo que significará" (Donoso, Cuaderno 6, 1957). Se refiere a la novela que publicará ese mismo año y no explica tal significado. En todo caso, la escena a la que alude es, sobre todo, de total irrelevancia argumental. Las historias de Misia Elisita, matriarca chilena olvidada, recluida, inhabilitada por su locura; así como la de Andrés Ábalos, su nieto abúlico y desencantado, no sufren mayores transformaciones directas a raíz de los eventos que se desarrollan en esta escena. Sin embargo, es tal su importancia que da título a la novela y trastoca el ambiente entero de la obra que hasta ese momento se desenvuelve al modo realista en que cada acción está claramente al servicio de la fábula. Al insertarlos en el terreno de lo sagrado, esta coronación dispone a sus habitantes para resoluciones finales que se precipitan en el exceso de la locura. Es un recurso que desafía la economía medida y proporcionada con que avanzaba la novela.

En Coronación (1957) se perfilan motivos que por su recurrencia en otras novelas se convertirán en una marca donosiana. La vieja matrona y la mujer creadora de seres a partir de retazos que se integran casi al azar ya están presentes en esta primera novela. Con orejas, patas y colas de felpa, Dora - cuñada de uno de los protagonistas- arma animales de peluche, de baja calidad y pobre gusto, características que conforman ese mundo del simulacro marchito que tanto le interesa al autor. A pesar de su impotencia y su pobreza, ella es percibida por su marido René y su cuñado Mario como un ser que quiere apresarlos. Representa la responsabilidad, lo correcto y la familia como cargas, otra recurrencia del autor. Huir de su sometimiento es la excusa que se adjudican estos hombres para el robo, esto es, para la trasgresión. En Dora confluyen dos motivos recurrentes: el sometido que a partir de su propia debilidad es percibido como una amenaza y la asociación entre mujeres y costura. Este es un hilo que retomará con las viejas de El obsceno pájaro de la noche (1970), donde estos motivos alcanzan su mayor grado de pesadilla. 
En la reseña de la novela, el reconocido crítico Hernán Díaz Arrieta (Alone) subraya la habilidad del autor para retratar con detalle un tema común como lo fuera la decrepitud de una clase y de un tipo de matriarcado. No solo eso, el elocuente reseñista defiende lo descarnado de la escritura y se refiere al comienzo de la novela, que empieza desde la cocina y con una cocinera. Lo hace a través de una declaración que no requiere argumentos: "La verdad es que empieza así, porque así debía empezar. Y no hay más razones" se lee en el periódico El Mercurio, del 19 de enero de 1958. Al tema de las cocineras y de ese mundo que dirige los altos designios de una casa volverá Donoso, fascinado, en diversas ocasiones.

El tema es, de hecho, un eje central en esta novela por dos motivos. El primero relacionado con Estela, la sirvienta más joven, quien concentra el deseo de experiencia y la experiencia del deseo que comprometen la natural comodidad y tibieza del señor Andrés. Justamente, la contemplación del color rosado de su palma desnuda abre la puerta de lo instintivo y lo salvaje hacia una intimidad inesperada. El segundo motivo es el hecho de que son las artes de las empleadas las que logran estremecer los cimientos de esa racionalidad que por tanto tiempo defendió a Andrés de sí mismo. El primer atisbo a esta capacidad de trastocar el orden se da, ni más ni menos, en la escena en que éste se anima a realizar las labores de limpieza junto a Lourdes.

En esta rarísima ocasión, Andrés se suma al oficio propio de las sirvientas. Abren las ventanas por donde entran rayos que iluminan un "hacinamiento de cosas descartadas por la vida" (144), se encuentra aquí una vez más la preeminencia del desecho. Esta actividad trae paz al largamente atribulado señor de la casa. Al abrir los baúles salen las cosas recluidas en el polvo y con ellas "la época en que tuvieron una vida activa se precipitó entera en el momento presente" (145). Una declaración sobre el poder de las cosas para trastocar los tiempos. La escena nos muestra a Andrés disfrazado con una capa española -de española, a propósito, será el vestido transformador de Manuela en El lugar sin límites (1967) -. Sale del desván con una débil máscara hecha de polvo y tiznes que muestra corporalmente la transformación que ha venido sufriendo. Más que eso, esta escena es el germen de la coronación, puesto que explica la procedencia del vestido, guardado y olvidado allí por años; y de la idea de llevar a cabo el deseo de Misia Elisita. Realizar el sueño de la abuela de ser coronada y celebrada es el plan que surge en las criadas tras remover estos viejos cachivaches.

Con una edad que nadie recuerda con claridad, lo que bien evoca la inexactitud del mito, y desde su cama a la que se refieren como nave, la 
abuela nos remite a Caronte ${ }^{4}$ en tanto agente mediador que transporta a los seres de un lado al otro. Ella, por su parte, habrá de llevarlos de la cordura a la locura, de la sobriedad a la embriaguez, de la pureza a la lujuria. Al apuntar hacia el castigo, ambigua, Misia Elisita devela también la seducción de la trasgresión. Para coronarla son usados materiales que provienen del desván, el lugar más alto de la casa que ha estado clausurado y olvidado. A la parte baja de la mansión son llevados todos los cachivaches para fabricar las flores, el vestido y la corona que en su miseria y caducidad suscitan la risa dolorosa. El objeto que habrá de sacralizarse es retirado de la esfera de lo profano y sufre una acción que implica su rebajamiento. Una especie de rito de polución que en este caso se concreta en una metáfora espacial implícita en el descenso.

¿Cuál es la desazón que viene a ocupar el tiempo de Andrés, un solterón de más de cincuenta años que ha vivido en una tibia tranquilidad toda su vida? ¿Dónde radica el fundamento de ese malestar? La última vez que Andrés durmió en casa de su abuela -y el narrador se refiere a este hecho con "sucumbir a la tentación"- algo como una presencia perturbó su lectura de Memorias de Saint-Simon: era Misia Elisita que pronunciaba palabras que eran "violencia, sorna, cólera, desesperación" (42).

A partir de allí, este hombre siente que la locura de su abuela ha llegado para quedarse y que ya no puede serle ajena. No es esta la primera ocasión en que las palabras de la anciana lo turban, sin embargo. También cuando ella habla con desfachatez de la muerte al poner de manifiesto esa posibilidad real que él ha insistido en negar. Esta vez, lo que más molesta a Andrés es que esas palabras estén desprovistas de significación. La palabra de su abuela desequilibra porque es ininteligible y obscena: irreductible al significado es perturbadora porque señala un abismo. Se trata de la calidad de la palabra en su aspecto mágico, al funcionar como objeto-misterio. La palabra como objeto que penetra y ensucia aquello que toca, de ahí que la casa entera contagiada se convierta en una amenaza para Andrés.

El aspecto material de la voz y su carácter sacro se vinculan en la novela a una fuerte caracterización y delimitación de los espacios. En tanto causa y efecto de lo sagrado funciona una clasificación que divide a los espacios entre

4 Según la mitología griega, Caronte es el barquero encargado de transportar las almas de los muertos a través de la laguna Estigia hasta el reino del inframundo gobernado por Hades. 
limpios y sucios atada a la capacidad de contagio de la palabra. Por ejemplo, la voz del padre Damián no penetra en el baño del colegio por ser un lugar sucio, el infierno al que no debe entrar la voz de un santo. Andrés acudía al baño cuando era niño, precisamente, como una manera de huir de todo lo que representaba el clérigo. Con el tiempo, aprendió a "no oír", a "no ver" lo que despertaba ese terror sagrado. Fue entonces cuando dejó de refugiarse en la suciedad y se aplicó al "convencimiento racional" para encubrir los temores de su infancia. Es una época a la que solo vuelve mediante el sueño, a través del cual continúa una búsqueda que lo preocupa desde la vigilia: "llegar a la otra orilla", sin desembocar apenas en la "interrogante de la muerte" (62).

$\mathrm{Su}$ amigo Carlos aparece como el contrapunto sobre el que reluce la apatía y la pasividad del protagonista. Más dado a las pasiones y a vivir intensamente, no extraña que sea descrito en términos que sugieren una religiosidad del placer: "como un sacerdote rechoncho y muy antiguo que oficiara en el templo de la satisfacción" (129). Su manera de entregarse a la vida intensamente revela un matiz menos profano, a tono con las preocupaciones que discutirá con Andrés. Ante las cavilaciones de su amigo acosado por el reconocimiento de que no ha vivido a profundidad, Carlos expresa críticas y argumentos que lo instan a la acción. Sin embargo, estas explicaciones y pruebas no producen en Andrés el efecto que logra la voz ininteligible de su abuela, una voz que lo hace sentirse asediado. Aunque la descripción del amigo sugiera el ministerio del placer, éste no alcanza el mismo rango de autoridad y fuerza que reside en la palabra de la abuela loca.

Acaso el gesto que mejor resume el talante con que Andrés aborda el placer se refleje en su relación con los bastones. A pesar de ser su pasión, ha mantenido la regla que él mismo se impuso de que su colección no sobrepase más que diez. Así, cuando encuentra uno nuevo que lo atrae prefiere deshacerse de alguno antiguo para lograr mantener el límite: Andrés es un esclavo de la templanza, de risa "convulsionada pero silenciosa" (74). Esta continencia es lo que le reclama su amigo y es el reproche que presiente en las palabras turbias de su abuela, en las que percibe el llamado sacro del desborde. Es cierto que la novela construye sus cimientos sobre el tema de las clases y la decadencia burguesa, como ha sido ampliamente señalado. No es menos perceptible, con todo, el empeño en la nomenclatura relativa a lo sagrado: semidios, semidemonio, deidad doméstica. Palabras que aparecen en la novela y que no pueden dejarse de lado en el entorno de esa "tragedia folletinesca" -así definida por su amigo- que vive este protagonista. Las máscaras y disfraces, tan donosianos, se presentan en diversos momentos a través de la novela. 
En una escena, por ejemplo, Estela contemplará maravillada el antifaz que cubre a un soldador. Estas formas del simulacro se inscriben, por tanto, en una índole decididamente ritual que escoge entre lo profano algunos elementos para rebajarlos y luego sacralizarlos.

Es en esta trama donde debe situarse la fuerza que posee la visita al anticuario. Encendido ya el deseo de comprar un nuevo bastón y con ello de rebasar el número de su muestrario, Andrés se rebela contra sus propios preceptos y acude a la casa de este hombre enjuto y de su mujer "vasta y madura" (110). Descrita con rasgos humorísticos, la pareja representa la unión de los extremos y llama la atención por la pureza de su trato que más parece el de una madre con su hijo. Más adelante, el narrador prefiere invertir dicha inocencia al designarlo como "una relación incestuosa que a ambos hacía muy felices" (110). Aunque no hay, dentro del orden de lo factual, algo que revele tamaña trasgresión, el lenguaje logra ese cambio de énfasis. A través de su pura fuerza performativa instituye la violación del tabú en el par de personajes a quienes los ojos lectores ya no podrán ver de la misma forma tras esa apreciación. El chal que Andrés le regaló a su abuela, así como la palma muelle y rosada de Estela convergen, invertidos, en la "grotesca" mujer del anticuario. A través de la crudeza del revés de su mano - de profunda connotación esotérica y anímica, húmeda e íntima-convoca la presencia de la muchacha. A partir de allí, el soltero Ábalos empieza un camino que avanza por la confesión ante el amigo Carlos y que terminará en su regreso a la casa, internándose cada vez más en el reino de la locura, propuesto por la abuela.

Ahora bien, durante la novela se hace referencia a tragedia una y otra vez para referirse a la crisis que vive Andrés, algunas veces con tono irónico y otras como una manera de sentir hondamente. Sin embargo, y como lo advierte Carlos, es apenas tragedia folletinesca que todavía carece del deseo de arriesgarse por lo que termina siendo apenas una ficción de tragedia: "Te crees un filósofo y no eres más que un histérico" (158), declara el doctor. La desesperación sigue siendo demasiado racionalizada, demasiado ponderada y pensada. Ha creado una "desazón" a medida, un malestar que le ofrece la ilusión de sentir algo para no enfrentar la verdad que significa moverse a la acción y sentir en realidad. Es decir, ese "llegar al otro extremo" no puede provenir de una concienzuda reflexión acerca de sobrepasar el límite. El requisito es la acción, intentar enamorar a Estela y adentrarse en el terreno de la experiencia de vivir.

¿Cuándo se opera esa transformación en que el personaje, finalmente, se decide a entrar en el terreno de la experiencia? El narrador recalca el adverbio 
ahora para designar cierta transformación: "Y Andrés sabía ahora que sólo lo incompleto, y por lo tanto lo que necesita, está vivo" y unas pocas líneas adelante: "Entonces Andrés Ábalos enunció la pregunta en que conjugó todo su ser..." (209). La pregunta era sobre los sentimientos de Estela y contiene una declaración de vulnerabilidad. En este momento, no solo Andrés alcanza su epifanía, sino también la muchacha cuya dignidad se agita. El narrador admite: "la mano del mal los había alcanzado a todos, estaban confundidos en sus desesperaciones solitarias..." (209).

Lejos de ser una simple casualidad, el telón de fondo de este momento es la celebración de las sirvientas Lourdes y Rosario. Este ritual establece una relación de causalidad de contigüidad con la transformación del espacio y el tiempo de la casa. Ellas son las figuras danzantes que llevan a cabo la fiestecita. Es en el contexto de la coronación que Andrés se arriesga a proponerle algo a Estela y que ella se da cuenta de estar siendo usada por su novio; mientras tanto Mario y René intentan robar la casa. La ceremonia sirve como marco para los reconocimientos y las transformaciones. Una coronación descrita cuidadosamente con las características del ritual: presencia de flores en el recinto, esmero en lo referente a las vestimentas, diligencia en el uso de la luz que aísla la figura de la coronada, música y chirridos de fonógrafo que, por supuesto, no se corresponden con la época. El rito transmuta el tiempo y el espacio, y con ello, la casa entera accede a otra atmósfera que tiene efecto en los seres, incluso en aquellos que están fuera del ritual.

No es ésta, claro, una celebración común sino una versión degradada, retorcida y cómica. Las sirvientas han insistido en que sea llevada a cabo de noche y solo ellas -Lourdes ha sido descrita como una deidad doméstica y criolla- asisten a la fiesta. Estela rechaza la invitación. Las dos mujeres, de natural equilibrado y compuesto, en esta noche singular se emborrachan al cuidar del ponche, pelean y se disfrazan. Ellas son las únicas atentas a la ocasión. Al cumpleaños cada vez asisten menos personas, sobre todo porque el señor Dionisio -siempre presente en la fiesta- ha muerto el año anterior, según ellas lo comentan. La escena, como se ha visto, potencia el uso de los disfraces al insertarlos en el ambiente de una celebración con carácter sagrado, parodia de lo mítico.

Ambas criadas, livianas como el aire, aladas e ingrávidas, comenzaron a danzar. Se pavoneaban, riéndose a carcajadas, dando pequeños brincos, haciéndose saludos mutuos, reverencias, genuflexiones, agitando los brazos, las manos, contoneando sus cuerpos como bayaderas, coreando infantilmente la melodía del fonógrafo (202). 
La imagen de Lourdes que pierde sus anteojos y de Rosario que les da un puntapié mientras las dos ríen promueve, claro, un efecto ridículo. Más que eso, convoca un eco de Tiresias y Cadmo, los dos viejos sabios que advierten sobre el agravio hecho al dios del vino. Además, la preocupación excesivamente racional de Andrés se asemeja a las funestas reservas de Penteo frente al culto dionisiaco. Las Bacantes, como explica Charles Segal, refleja el conflicto entre los modos mítico y conceptual de pensamiento, profundamente marcados en la historia intelectual del ocaso del siglo V (Segal 273). El ánimo por la fiesta y el rito que el mito griego promueve será parodiado en su máxima expresión donosiana a través de Manuela en El lugar sin límites ${ }^{5}$. La afinidad y alianza entre Dionisio y las mujeres es tan fuerte y ambigua como la que se desarrolla a lo largo de la poética donosiana. Dionisio libera todo el poder femenino en las montañas y Donoso lo asienta en la casa, un contraste que lo mismo vuelve doméstico a lo salvaje como hace agreste el espacio familiar.

De modo que estas dos mujeres no pueden menos que presentar una versión rebajada e irónica de los bacanales: "Un poco después, con las cabelleras revueltas y los tocados de pluma en jirones, enrojecidas y palpitantes y sudorosas, las criadas se dejaron caer sobre la cama" (203). Es, después de todo, un bacanal sin Dionisio. Son populares bacantes santiaguinas, de corona y vestiduras hechas con harapos que se han empezado a dañar, sacados del tiempo que habitaba un baúl olvidado. Las pobres terminan por dejar de lado a la reina que reposa "con la cabeza volcada hacia adelante y la corona de plata chueca sobre el rostro pintarrajeado" (202). A pesar de que la celebración puede parecer endeble, puro remedo de solemnidad, el hecho de que se desencadenen las transformaciones a partir de ella da cuenta de su poder. No se trata de restringir lecturas en una obra tan polivalente como el mismo dios que la protagoniza, ni de entender la novela como una parodia a pie juntillas. Se trata de resaltar la evidente reflexión sobre el lugar y la función de estas formas de pensamiento tanto en Eurípides como en Donoso.

De modo que la coronación no contribuye en la relación causa-efecto. Se trata de la contigüidad que se establece entre la fiesta de las sirvientas y la transformación de Andrés, con talante de experiencia mítica. El cumpleaños alcanza el tono del ritual y por esto crea una atmósfera que se aparta del mundo

Abordo este tema en mi tesis doctoral "Formas del vértigo: una estética donosiana" (USP, 2017) Beca Cnpq, orientada por la Prof. Dra. Laura Janina Hosiasson, de la que este artículo hace parte. 
ordinario; en ese sentido, las sirvientas convierten la celebración rutinaria en un acto sagrado. En la forma de la novela, construida cuidadosamente para que cada acción impacte el desarrollo de una lógica que corresponde al pensamiento teórico, algo también se transforma por esta coronación. Giorgio Agamben argumenta que profanar significa tanto darle un nuevo uso a las cosas, como imitar sus formas "vaciándolas de sentido y de la relación obligada a un fin" (112-113). Al desactivar la dinámica de la narración sometida a la evolución del argumento con una escena que no lo está, el autor profana la palabra realista ${ }^{6}$ y abre la posibilidad del efecto en los lectores. Para quien ya acompaña la experiencia metafísica del personaje, el cambio que se da en la forma del relato puede generar una extrañeza, una respuesta emotiva, pues "cuán atroz e inquietante puede ser un juguete, cuando el juego del que formaba parte ha terminado" (Agamben 113).

Dionisio, el dios que se encarga de confundir y disolver los límites, juega con las fronteras entre lo divino y lo humano, entre la razón y la locura. Penteo sufre la transformación, Andrés se entrega a la locura; rendirse al placer es la cuestión fundamental a la que se ven enfrentados. Estela se va y la desesperación de Andrés toma otras dimensiones pues logrará convencerse a sí mismo de estar tan loco como su abuela: "como si por fin, al darse cuenta de su locura y aceptarla, fuera capaz de huir de toda responsabilidad, aun la de separar lo real de lo ficticio" (214). Algo cambia para siempre y es que esta vez logra convencer de su locura al amigo, pues empieza a vivir una "verdad" en la que cree y en la que quiere creer. Es la ficción que crea, al estilo dionisiaco de la ilusión artística. Carlos termina dándole la razón al loco y aceptando, como si fueran ciertas, cosas que sabe que no lo son. La locura de Andrés logra imponérsele, al menos, en lo que se refiere al territorio de la casa y el asunto queda resuelto tras la sentencia del médico. En un ambiente tan trágico como este, solamente la locura tiene la "última palabra" y sugiere la liberación del protagonista.

La muerte de Misia Elisita refleja el deterioro de cierta clase, de una forma de vida donde cabía este tipo de matriarca, pero más que eso, es hacia otro tipo de extinción que apunta. Lo mismo que en la obra de Eurípides, a la que parodia, la novela plantea el ocaso que sufren los ritos y la posibilidad de un retorno a ellos. Aunque parezcan agonizar, ellos contienen fuerza.

6 La idea de la palabra realista profanada hizo parte de las recomendaciones dadas durante la evaluación ciega por pares realizada a este artículo. Agradezco la sugerencia. 
Su facultad para transformar permanece y su aptitud para conducir al "otro extremo" que se aleja entre verdades y miedos. Esa orilla que se vislumbra desde el espacio del sueño, tal como le sucede al protagonista.

El hecho de que Donoso añada en la entrevista con Rodríguez Monegal (519) que Coronación tal vez no sea "en el fondo" una parodia porque está demasiado metido en la novela como para poder parodiarla, confirma que su concepto de parodia implica otros significados. A través de ella efectúa un rebajamiento que impacta en el efecto de cercanía que establece con el lector, pero otra posibilidad se desprende.

La definición de uso más generalizado concibe a la parodia como un modelo que se transforma de serio a cómico en el que se integran contenidos nuevos e incongruentes. Es un concepto relativamente moderno, derivado de la Poética de Escalígero (1561) (Cit. en Agamben 2005). En su acepción más antigua, se refiere a la separación entre la música y el lenguaje, lo que abre un espacio contiguo destinado a la prosa. Agamben entiende la parodia no como la transposición de lo serio sino como único medio para acceder a un objeto de deseo. El hombre estaría sometido a habitar una historia que no le pertenece, por consiguiente, todo objeto de narración será de manera forzosa paródico. Al representar lo que no puede ser narrado, la parodia asume "la forma misma del misterio" (Agamben 52). De allí, el filósofo deriva su idea de la parodia como posibilidad única de evocación.

\section{A MODO DE CIERRE}

La apuesta donosiana consiste en una parodización de elementos de carácter trágico y no tiene como único destino la risa ni conlleva necesariamente la pérdida de su potencial patético. Por fuera de la grandilocuencia, estas formas y temas se renuevan sin perder su capacidad para mover a la emoción. La escritura de José Donos muestra que la gravedad no es exclusiva de la pompa. Es parodia en tanto rebaja los grandes temas al robárselos a la solemnidad pura, como único camino para adentrarse a aquello que permanece desconocido e indeterminado.

El proyecto donosiano procura suscitar una experiencia de carácter ritual (en la estructura interna de la obra, experimentado por los personajes y, a través de ellos, por el lector). La materia ficcional que ofrece el despojo es usada por el autor para realizar actos de sacralización y desacralización 
que le permiten desplegar una escritura que revitaliza el mito de manera contemporánea. A través de una construcción que gestiona formas estéticas propias de su tiempo, Donoso ha logrado incorporar formas de pensamiento engendradas por fuera de ese mismo tiempo que, en realidad, lo sobrepasan.

\section{BIBLIOGRAFÍA}

Agamben, Giorgio. Profanações. Buenos Aires: Adriana Hidalgo, 2005.

Blanchot, Maurice. El libro que vendrá. Venezuela: Monte Ávila Editores, 1959.

Cassirer, Ernst. Filosofía de las formas simbólicas. (1964). 2. ed. México: Fondo de Cultura Económica, 1971. $3 \mathrm{v}$.

Donoso, José. José Donoso Papers. Collection Dates: 1951-1967. Special Collections. Iowa University Library.

Conjeturas sobre la memoria de mi tribu. Santiago de Chile: Alfaguara, 1996. Coronación. (1957). Barcelona: Editorial Seix Barral, 1980. Este domingo. (1966). Barcelona: Seix Barral, 1982.

Eliade, Mircea. Mito y realidad. (1963). Madrid: Ediciones Guardarrama, 1973.

Frye, Northrop. Anatomy of Criticism: Four Essays. Princeton, N.J: Princeton University Press, 1957.

Goic, Cedomil. La novela chilena: los mitos degradados. Santiago: Editorial Universitaria, 1976. Gutierrez Mouat, Ricardo. José Donoso: impostura e impostación. Maryland: Hispamérica, 1983. Heath, Malcolm. The poetics of Greek tragedy. London: Duckworth, 1987.

Hutcheon, Linda. A theory of parody: The teachings of Twentieth-century art forms. Chicago: University Of Illinois Press, 2000.

Konstan, David. The emotions of the Ancient Greeks: studies in Aristotle and classical literature. Toronto: University of Toronto Press, 2007.

LaCourse Munteanu, Dana. Tragic pathos: Pity and Fear in Greek Philosophy and Tragedy. New York: Cambridge University Press, 2012.

Mulinacci, Roberto. No encalco do trágico: A tragédia, o romance e os paradoxos da modernidade literária. In: Finazzi-Agrò, Ettore; Vecchi, Roberto (Org.). Formas e mediações do trágico moderno: Uma leitura do Brasil. São Paulo: Unimarco, 2004. 161-174.

Rodríguez Monegal, Emir. José Donoso: "La novela como happening: una entrevista de Emir Rodríguez Monegal sobre El obsceno pájaro de la noche". Revista Iberoamericana [s. L.], v. 37. 517-536, 1971.

Schwartz, Elias. The forms of feeling: toward a mimetic theory of literature. Port Washington, N.Y. : Kennikat Press, 1972.

Segal, Charles. Dionysiac poetics and Euripides' Bacchae. Princeton, N.J: Princeton University Press, 1997. 
Steiner, George. La muerte de la tragedia. Caracas: Monte Avila, 1991 [1961]. 